\title{
Thermal reinforcement in the rat: The topography of operant leverpressing
}

\author{
GRAHAM C. L. DAVEY \\ The City University, London, England
}

\begin{abstract}
Three rats were trained to press a lever on a fixed-ratio 3 schedule to obtain a 4-sec burst of radiant heat in a cold environment. Control conditions suggested that this learning was dependent on the contingency between leverpressing and heat reinforcements, and the warming properties of the heat lamp reinforcer. Leverpressing in all subjects was characterized by relatively long-duration presses, and observations showed that more than half of the ratio runs contained leverpress topographies in which the subject remained immobile on the lever for greater than $4 \mathrm{sec}$ or used the lever as a support for rearing and sniffing. These results suggest that the low rates of responding on operant schedules of thermal reinforcement are accompanied by the development of leverpress topographies that are incompatible with high rates of responding.
\end{abstract}

A number of studies have demonstrated that thermal reinforcement in cold environments can be an effective operant reinforcer for leverpressing in rats (Carlisle, 1966, 1969, 1970; Corbit, 1970; Weiss \& Laties, 1960), but response rates are rarely as high as those found with food reinforcement (see Corbit, 1970). In particular, when the work requirement on fixed-ratio (FR) schedules is increased, rate of responding fails to increase sufficiently to maintain a constant heat intake, even at FR values lower than FR15 (Carlisle, 1969). Traditional accounts of this failure to compensate allude to interactions between the behavioral and autonomic components of the organism's thermoregulatory system (e.g., Carlisle, 1969; Hogan \& Roper, 1978); that is, when the work load per unit reinforcement reaches a critical ratio, it may be more beneficial for the animal to abandon behavioral means of thermoregulation in favor of autonomic ones (e.g., shivering).

There is, however, at least one other possible explanation for the poor performance of rats on ratio schedules of thermal reinforcement. It would seem reasonable, in light of the recent literature on constraints on learning, to investigate whether thermal reinforcement is accompanied by behaviors that are incompatible with high rates of operant leverpressing. A number of studies have shown that reinforcer-elicited behaviors that are incompatible with the operant response are responsible for the failure of subjects to learn the response (e.g., K. Breland \& M. Breland, 1961; Hoffman \& Fleshler, 1961; Schwartz \& Coulter, 1973; Sevenster, 1968) and, in some cases, responsible for the failure of animals to acquire characteristic "break-and-run" performance on FR schedules

The author is grateful to Paul Williams, Saeed Chaudri, and Gary Cleland for their help during this study. This research was partially supported by Science and Engineering Research Council Grant GR/C54876 to the author. Reprints may be obtained from Graham Davey, Psychology Division, Department of Social Science and Humanities, The City University, Northampton Square, London EC1V OHB, England.
(Hogan, 1967; Hogan, Kleist, \& Hutchings, 1970). There are two possible sources of competing responses in thermal reinforcement procedures with rats. First, rats are generally immobile in cold environments, which may lead to long breaks in responding when the rat moves away from the lever to huddle elsewhere in the chamber (see Griffiths \& Davey, 1984). Second, the unconditioned response to an overhead heat source is for the rat to partially rear with snout raised in the direction of the heat source and remain in an immobile "basking" posture during the period of heat presentation (Davey, Griffiths, \& Phillips, 1987; Griffiths \& Davey, 1984). When a leverpress produces the heat reinforcer, the immobile basking response may be reinforced, and that topography may become characteristic of leverpressing, producing longduration presses incompatible with the high rates of responding normally required by FR schedules.

The present experiment is an attempt to investigate the topography of leverpressing in rats on a simple FR schedule of thermal reinforcement and, in particular, to examine the frequency of long-duration leverpresses and resemblances between the topography of leverpressing and the reinforcer-elicited behaviors.

\section{METHOD}

\section{Subjects}

The subjects were 3 male Hooded Lister rats, approximately 150 days old at the outset of the experiment. They were all housed in individual home cages with ad-lib food and water in an animal holding room whose ambient temperature was maintained at $20^{\circ} \pm 2^{\circ} \mathrm{C}$. These subjects had previously experienced the cooled incubator in an autoshaping study using a retractable-lever CS and a thermal reinforcer, but none had exhibited any leverpressing or lever contact during this training.

\footnotetext{
Apparatus

The experimental environment consisted of a purpose-built aluminum chamber whose dimensions were $41 \mathrm{~cm}$ long $\times 23 \mathrm{~cm}$ wide $\times 30 \mathrm{~cm}$ high. On the longest wall of the chamber was mounted an aluminum lever, which was $6 \mathrm{~cm}$ above the grid floor and $9 \mathrm{~cm}$ from the left-hand wall. This lever was $3.8 \mathrm{~cm}$ wide, projected $2.2 \mathrm{~cm}$ into the chamber,
} 
and required a weight of approximately $8 \mathrm{~g}(0.78 \mathrm{~N})$ to record a press. A 250-W infrared heat lamp, situated centrally above the chamber approximately $23 \mathrm{~cm}$ from the grid floor, could be activated for 4-sec periods to provide radiant heat reinforcement. Situated approximately $50 \mathrm{~cm}$ above the grid floor of the chamber was a closed-circuit TV camera, which, with the use of a wide-angle lens, could relay TV pictures of the subjects to observers in an adjoining room. The experimental chamber and TV camera were housed in a cooled incubator where the ambient temperature was set at $0^{\circ} \pm 2^{\circ} \mathrm{C}$. General illumination in the cooled incubator was provided by a $15-\mathrm{W}$ lamp situated directly above the heat lamp. The experiment was controlled and the data collected by solid-state logic programming equipment situated in the adjoining room.

\section{Procedure}

For the first 2 sessions of operant training, all subjects were hand shaped by successive approximations to approach, contact, and finally press the lever to produce 4-sec illuminations of the heat lamp. By Session 4, all subjects were responding to produce the heat lamp illuminations on an FR3 schedule. Each session lasted for $\mathbf{4 5} \mathrm{min}$. By Session 10, response rate per session had stabilized (response rate on Sessions 7-10 did not differ by more than $10 \%$ from the mean of these four sessions), and on Session 11 all subjects were given one session in which the ambient temperature of the cooled incubator was raised to $20^{\circ} \mathrm{C}$ (comparable with the temperature in the animal holding room). During this session illuminations of the heat lamp were again produced by leverpressing on an FR3 schedule. Sessions 12-15 consisted of a return to the conditions operating during Sessions 4-10 (ambient temperature of $0^{\circ} \pm 2^{\circ} \mathrm{C}$ on an FR3 schedule). During Sessions 16-18 the contingency between leverpressing and heat lamp illumination was removed: all subjects received response-independent presentations of the heat lamp on a schedule whose temporal distribution was based on the rate of reinforcement each subject had achieved during the preceding 3 sessions of response-dependent reinforcement. Finally, the last 3 sessions (19-21) consisted of a return to response-dependent reinforcement on an FR3 schedule.

Observational procedures. On Sessions 7 and 10, the lever contact behaviors of all subjects were video-recorded and analyzed according to preselected topographical categories. Each behavior was scored on the basis of the percentage of ratio runs that contained at least one instance of the behavior. The topographical categories were the following: (1) sniff: contacting the lever with the snout, usually with movements of the vibrissae characteristic of sniffing an object; (2) brief paw contact: placing a paw or paws on the lever for a duration of $<4 \mathrm{sec}$; (3) sustained paw contact: placing a paw or paws on the lever and remaining relatively immobile for a duration of $\geq 4 \mathrm{sec}$; (4) rear and sniff. while using the lever for support, raising the snout and making movements of the vibrissae characteristic of scenting the air. From preliminary observations made during Sessions 4-6, it was clear that these

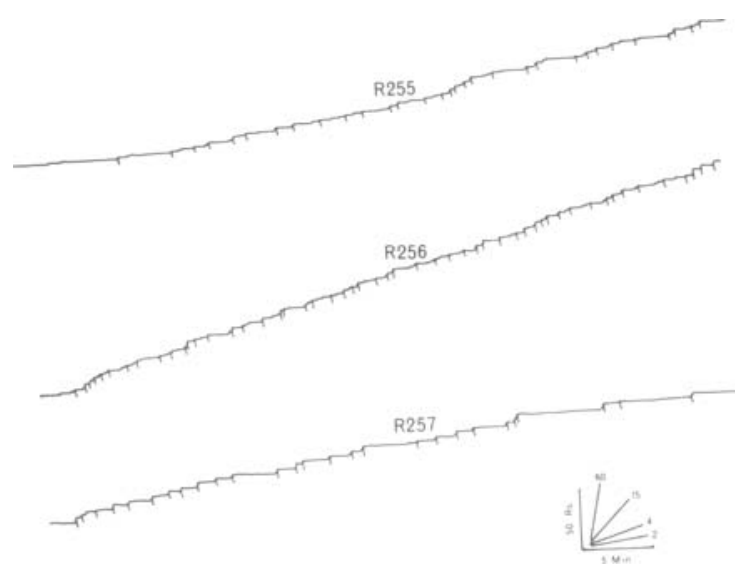

Figure 1. Cumulative records for Session 9 for all 3 subjects. Hatch marks denote the onset of the 4-sec reinforcement.
Table 1

Response Rates, Reinforcer Rates, and Mean Leverpress Duration for the Last Four Sessions Prior to Noncontingent Reinforcement (Sessions 12-15)

\begin{tabular}{lccc}
\hline Subject & $\begin{array}{c}\text { Responses } \\
\text { per Minute }\end{array}$ & $\begin{array}{c}\text { Reinforcements } \\
\text { per Minute }\end{array}$ & $\begin{array}{c}\text { Mean Press } \\
\text { Duration* }\end{array}$ \\
\hline R255 & 2.39 & 0.79 & 2.62 \\
R256 & 3.20 & 1.00 & 1.75 \\
R257 & 1.69 & 0.55 & 0.89 \\
Mean & 2.42 & 0.78 & 1.75 \\
ISEM & 0.43 & 0.13 & 0.49 \\
\hline
\end{tabular}

*Mean press duration is given in seconds.

categories covered all but a very small number of leverpress topographies. There were a few instances of body contact with the lever when subjects paused briefly to huddle by the lever; however, these were considered to be so infrequent as not to require tabulation. Detection of lever contact was aided by a drinkometer circuit connected to the lever, which illuminated a small 2.8-W bulb out of sight of the subject when the lever was contacted. Two observers scored the first observation session with $77.3 \%$ agreement between them, suggesting that the topographical categories were reliable and objectively defined. Scores given under Results represent the observations made by a single observer.

\section{RESULTS}

Over Sessions 1-10 of operant training, the mean ( \pm SEM) recorded temperature in the cooled incubator was $2.66^{\circ} \pm 0.68^{\circ} \mathrm{C}$ with a minimum recorded of $-4^{\circ} \mathrm{C}$ and a maximum of $10^{\circ} \mathrm{C}$.

By Session 10 all subjects were responding at a low but relatively constant rate throughout the 45 -min session. Figure 1 shows representative cumulative records for all 3 subjects taken from Session 9. Subject R257 exhibited a few relatively lengthy pauses in responding toward the end of the session, but by and large, breaks in responding were usually less than $90 \mathrm{sec}$. Table 1 summarizes the quantitative data from the last four sessions on FR3 prior to noncontingent reinforcement. Response rate was low (mean 2.42 responses/minute compared with rates normally sustained by food reinforcement, but was not excessively low when compared with the rates of responding found in other thermal reinforcement studies (e.g., Carlisle, 1969; Weiss \& Laties, 1960). Mean ( \pm SEM) press duration for all 3 subjects was $1.75 \pm 0.49 \mathrm{sec}$, a duration that is relatively long when compared with response duration for food reinforcement (cf. Hull, 1977). In the case of Subject R255, the mean press duration of $2.62 \mathrm{sec}$ would have set a ceiling to this subject's response rate of 22.9 responses/minute even if no pausing had been evidenced.

Table 2 summarizes response rate data for selected sessions toward the end of the experiment. All subjects showed a substantial decrease in response rate during the session when the ambient temperature of the cooled incubator was raised to $20^{\circ} \pm 2^{\circ} \mathrm{C}$ (Session 11), but resumed their original rate of responding when the temperature was subsequently lowered again to $0^{\circ} \pm 2^{\circ} \mathrm{C}$ (e.g., Session 15). At this point in the experiment, Subject R255 died and the remaining 2 subjects went on to experience response-independent thermal reinforcement for three ses- 
sions. Both subjects exhibited a substantially reduced rate of leverpressing during noncontingent reinforcement, and by Session 18, their response rates were the lowest recorded for any session of the experiment. Response rate again recovered, however, when the contingent reinforcement was reinstated for the final three sessions (Session 21).

Finally, Table 3 shows the observational data relating to leverpress topography. Paw contact was the most predominant response topography; it frequently took the form of resting the paws on the lever and remaining immobile. Sustained paw contact of this type occurred during over half of the ratio runs (mean $=52 \%$ ). Over half of the ratio runs were also characterized by leverpressing accompanied by rearing and sniffing, with paws resting on the lever. Both of these topographies were incompatible with rapid rates of leverpressing since, as is the case in most operant conditioning chambers, the lever must return to its normal resting position before an additional press can be recorded.

\section{DISCUSSION}

These results show that: (1) rats learn to press a lever to produce thermal reinforcement, and this learning is dependent on the contingency between response and reinforcer, and a cold environment; (2) as in other thermal reinforcement studies, response rates were relatively low compared with comparable rates found for food reinforcement; and (3) this low rate of responding appears in part to be the result of leverpress topographies that are not compatible with rapid response rates: these topographies include remaining immobile on the lever and rearing and sniffing while using the lever for support. This latter topography is very similar to the basking response to overhead heat reinforcement found in other thermal conditioning studies with rats (Davey et al., 1987; Griffiths \& Davey, 1984).

The fact that over half the ratio runs contained leverpress topographies that generated long-duration presses is theoretically interesting in that it constrains the rate at which rats can effectively acquire thermal reinforcement on FR schedules, and is consistent with the failure of rats

Table 2

Mean Rate of Leverpressing (Responses/Minute) for All 3 Subjects for Selected Sessions During the Last 11 Sessions of the Experiment

\begin{tabular}{lccccc}
\hline & \multicolumn{5}{c}{ Session } \\
\cline { 2 - 6 } & $10^{*}$ & $11 \dagger$ & $15^{*}$ & $18^{*}$ & $21^{*}$ \\
\hline Response Contingency & Yes & Yes & Yes & No & Yes \\
R255 & 2.35 & 0.37 & 2.81 & - & - \\
R256 & 1.75 & 0.37 & 4.31 & 0.26 & 2.75 \\
R257 & 2.55 & 0.26 & 1.42 & 0.53 & 2.25 \\
Mean & 2.21 & 0.33 & 2.84 & 0.39 & 2.50 \\
\pm SEM & 0.24 & 0.03 & 0.83 & 0.13 & 0.25 \\
\hline
\end{tabular}

Note-Subject R255 died following Session 15 of training. *Ambient temperature $=0^{\circ} \pm 2^{\circ} \mathrm{C}$. †Ambient temperature $=20^{\circ} \pm 2^{\circ} \mathrm{C}$.
Table 3

Mean Probability of Each Leverpress Topography Occurring During a Ratio Run

\begin{tabular}{lcccc}
\hline \multicolumn{5}{c}{ Topography } \\
\hline Subject & Sniff & Rear and Sniff & $\begin{array}{c}\text { Brief } \\
\text { Paw Contact } \\
(<4 \mathrm{sec})\end{array}$ & $\begin{array}{c}\text { Sustained } \\
\text { Paw Contact } \\
(>4 \mathrm{sec})\end{array}$ \\
\hline R255 & 0.38 & 0.64 & 0.62 & 0.74 \\
R256 & 0.50 & 0.47 & 0.85 & 0.56 \\
R257 & 0.40 & 0.57 & 0.84 & 0.28 \\
Mean & 0.42 & 0.56 & 0.77 & 0.52 \\
\pm SEM & 0.03 & 0.04 & 0.07 & 0.13 \\
\hline
\end{tabular}

Note-Data are combined from observations taken on Sessions 7 and 10.

to maintain a constant heat intake when FR values are increased (Carlisle, 1969; Corbit, 1970). There are a number of processes that might plausibly generate topographies that lead to long-duration presses.

First, long-duration presses may represent an energysaving strategy in an environment in which the trade-off between energy expenditure and heat procurement must be critically regulated. Vigorous manipulation of the lever is obviously energy consuming, and when the work rate per reinforcer is increased (e.g., by increasing the FR value), it may become more expedient to use autonomic rather than behavioral means to conserve heat (see Carlisle, 1969; Hogan \& Roper, 1978).

Second, many of the characteristics of the leverpressing topographies resembled rats' rearing and basking responses to presentation of an overhead heat source (e.g., Davey et al., 1987; Griffiths \& Davey, 1984). Through a process of Pavlovian conditioning, these unconditioned responses to a heat US may have become conditioned responses elicited by stimuli signaling heat presentation. Stimuli capable of acquiring such properties include features of the operant manipulandum itself or temporal stimuli indicating time since the last reward. Both of these factors have been shown to evoke UCS-related behaviors in other operant situations (e.g., K. Breland \& M. Breland, 1961; Boakes, Poli, Lockwood, \& Goodall, 1978; Staddon \& Simmelhag, 1971).

Third, lever-holding strategies may have resulted from adventitious reinforcement of basking responses performed on the lever. During presentation of the heat reinforcer, subjects were frequently observed to remain immobile with their paws on the lever, sniffing upward toward the heat source for the full $4 \mathrm{sec}$ of its illumination. Such conditions could be highly conducive to the adventitious reinforcement of response strategies that resulted in long-duration presses. There is other evidence that is consistent with this possibility. For instance, rats are perfectly capable of maintaining a constant heat intake when heat duration is controlled by duration of a single response (Carlisle, 1966; Corbit, 1970; Leeming, 1968). This suggests that rats are not incapable per se of regulating heat intake by behavioral means, and a contingency between response duration and heat duration allows the operant to be compatible with basking. Also, 
relatively high rates of leverpressing on FR schedules can be obtained when very short $(\leq 1 \mathrm{sec})$ thermal reinforcer durations are used (Carlisle, 1969; Weiss \& Laties, 1960). According to an adventitious reinforcement account of lever-holding topography, a 1-sec heat presentation would not permit long duration presses to be reinforced and would thus allow higher response rates to occur. Additionally, when the ratio requirement has to be fulfilled on a lever that is different from that which procures the heat reinforcer (e.g., a chain FRn:FR1), high rates of responding can be obtained on the first component (Carlisle, 1970), and reasonably good compensation can be obtained on schedules up to chain FR64:FR1. This would be predicted by an adventitious reinforcement account, since lever-holding could only be reinforced on the lever that operates the heat reinforcer.

Finally, although it is clear that long-duration press topographies do accompany low-rate responding for heat reinforcement (as opposed to short-duration presses with long interpress intervals), the results of the present study do not necessarily indicate a causal relationship between the two. It is quite conceivable that some other factor may cause low response rates and that long-duration press topographies may develop to fill the interresponse intervals. However, the fact that high response rates can be obtained with thermal reinforcement (e.g., Carlisle, 1969, 1970) does suggest that low-rate responding is not an inevitable effect of thermal reinforcement as some explanations of thermoregulation may suggest.

In summary, this study shows that the low response rates obtained on ratio schedules of thermal reinforcement are accompanied by operant response topographies that are incompatible with high rates of responding. These topographies resemble behaviors normally elicited by heat reinforcement, and such results are consistent with the suggestion that the failure of rats to increase response rates to maintain a constant heat intake on ratio schedules may result from interactions between the operant response and reinforcer-elicited behaviors.

\section{REFERENCES}

Bonkes, R. A., Pou, M., Lockwood, M. J., \& Goodall, G. (1978). A study of misbehavior: Token reinforcement in the rat. Journal of the Experimental Analysis of Behavior, 29, 115-134.
Breland, K., \& Breland, M. (1961). The misbehavior of organisms. American Pychologist, 16, 661-664.

CARusLE, H. J. (1966). Heat intake and hypothalamic temperature during behavioral temperature regulation. Journal of Comparative \& Physiological Psychology, 61, 388-397.

CarLisLe, H. J. (1969). Effect of fixed-ratio thermal reinforcement on thermoregulatory behavior. Physiology \& Behavior, 4, 23-28.

CarlisLe, H. J. (1970). Intermittent heat as a reinforcer for rats in the cold. Physiology \& Behavior, 5, 861-866.

CoRBIT, J. D. (1970). Behavioral regulation of body temperature. In J. D. Hardy, A. P. Gagye, \& J. A. Stokwijk (Eds.), Physiological and behavioral temperature regulation (pp. 777-801). Springfield, IL: Thomas.

Davey, G. C. L., Griffiths, S., \& PhIlliPs, J. H. (1987). Signaldirected behaviour in rats using a thermal reinforcer. Paper submitted for publication.

GrIFFITHS, S., \& DAVEY, G. C. L. (1984). Signal-directed behavior in rats using a heat UCS. IRCS Medical Science, 12, 1060-1061.

Hoffman, H. S., \& Fleshler, M. (1961). The course of emotionality in the development of avoidance. Journal of Experimental Psychology, 64, 288-294.

HogAN, J. A. (1967). Fighting and reinforcement in the Siamese fighting fish (Betta splendens). Journal of Comparative \& Physiological Psychology, 70, 351-357.

Hogan, J. A., Kleist, S., \& Hutchings, C. S. L. (1970). Display and food as reinforcers in the Siamese fighting fish (Betta splendens). Journal of Comparative \& Physiological Psychology, 70 351-357.

HogAN, J. A., \& Roper, T. J. (1978). A comparison of the properties of different reinforcers. In J. S. Rosenblatt, R. A. Hinde, C. Beer, \& M. C. Busnel (Eds.), Advances in the study of behavior, 8, 155255. New York: Academic Press.

HuLL, J. H. (1977). Instrumental response topographies of rats. Animal Learning \& Behavior, 5, 207-212.

LEEMING, F. C. (1968). Response rate as a function of magnitude and schedule of heat reinforcement. Joumal of Experimental Psychology, 76, 74-77.

SChWARTZ, B., \& Coulter, G. (1973). A failure to transfer control of keypecking from food reinforcement to escape from and avoidance of shock. Bulletin of the Psychonomic Society, 1, 307-309.

SEVENSTER, P. (1968). Motivation and learning in sticklebacks. In D. Ingle (Ed.), The central nervous system and fish behavior. Chicago: University of Chicago Press.

Staddon, J. E. R., \& Simmelhag, V. L. (1971). The "superstition" experiment: A re-examination of its implications for the principles of adaptive behavior. Psychological Review, 78, 3-43.

WeIss, B., \& LATIES, V. G. (1960). Magnitude of reinforcement as a variable in thermoregulatory behavior. Journal of Comparative \& Physiological Psychology, 53, 603-608.

(Manuscript received for publication November 10, 1986.) 